\title{
Vietnamese EFL Students' Perceptions of Noticing-Based Collaborative Feedback on Their Writing Performance
}

\author{
Trang Thi Doan Dang ${ }^{1}$ \\ ${ }^{1}$ Faculty of Education, Monash University, Australia \\ Correspondence: Trang Thi Doan Dang, G16, Building 6, Monash University, Clayton campus, Victoria 3800. \\ E-mail: tddan4@student.monash.edu
}

Received: February 28, 2016

Accepted: April 10, 2016 Online Published: April 11, 2016

doi: $10.5539 /$ elt.v9n5p141

URL: http://dx.doi.org/10.5539/elt.v9n5p141

\begin{abstract}
It has been theoretically and empirically acknowledged that collaborative feedback is beneficial to learning achievement. However, feedback research remains relatively contentious due to learners' differing viewpoints on how feedback is best given. Although a large number of studies have explored learners' perspectives on collaborative feedback, little classroom-based research has promoted noticing through collaborative feedback. To address this, this study aims to infuse noticing-based collaborative correction into secondary classrooms to explore students' perceptions of such feedback practice on their written output. Forty-one students' responses to the list of close-ended questionnaires revealed a strong consensus about this potential approach although there are indications that the participants' dependent learning styles had influenced these findings. An obvious implication of this is that students might benefit from various scaffolding sources, and thus there is a need for teachers to be aware of the influence of reciprocal learning among learners so that the quality of feedback practices may be enhanced.
\end{abstract}

Keywords: feedback, noticing, collaboration

\section{Introduction}

Feedback has attracted much attention in recent educational research because of its significant contributions to the teaching and learning process. Feedback not only helps teachers to monitor the objectives of a course and students' needs but also plays a key role in guiding and encouraging students' motivation (Hyland \& Hyland, 2006). Learners may not be able to enhance their language skills if they do not receive feedback on performance. In other words, feedback encourages learners to look closely and critically at their own performance and promotes error correction. In a practical sense, corrective feedback is widely known as a constructive tool or as a "noticing facilitator" (Van Beuningen, 2010, p. 5).

In writing, feedback can be seen as a lens through which to view the gaps or mismatches of language use. It can be classified into teacher feedback (TF), self-feedback and peer feedback (PF). Feedback, regardless of what form it occupies, is of paramount importance for the development of writing skills, for both motivation and consolidation of these skills (K. Hyland \& F. Hyland, 2006). One popular form of feedback is error correction (EC), occurring when learners are overtly notified of the presence of an error in their writing and are given the target-like reformulation in response to their writing (Ferris, 2011). Additionally, PF is referred to as "instructional scaffolding feedback", enabling learners to achieve better insights regarding their needs or gaps and in turn helping them edit their writing following the feedback (Barnawi, 2010, p. 211). Feedback is thus considered a vital strategy to enable writers to produce a good writing product, and it is absolutely essential to know what students think about such tactic. However, feedback practice is not highly motivated in Vietnamese high schools and it is a challenging task for students.

From a cognitive perspective, noticing occurs while learners pay attention to language input and output and is considered an essential condition for language learning (Schmidt, 1990, 2001). Noticing, known as 'noticing the gap' enables learners to be aware of a gap between a learning product and a desired outcome, as well as between their own learning output and a target product produced by native speakers. Schmidt (2001) has noted that without noticing learning cannot take place and argues that learners can learn about the things they consciously pay attention to but are unable to learn sufficiently about what they do not consciously focus on in this way. Thus, noticing may have a close relationship with other aspects in second language (L2) learning and facilitate 
corrective feedback in drawing learners' attention to language use. Given such a positive characteristic of noticing in L2 learning, one might question: 'What happens if noticing is incorporated into collaborative correction?' and 'What do students think of noticing and collaborative correcting skills?'

In fact, research has shown that learners' perspectives may have been influenced by the way written corrective feedback (WCF) is delivered. Such comparative studies identified learners' perceptions of the degree to which WCF (i.e., teacher and peer feedback) measured the degree to which they considered feedback as effective and important to their learning process, but also revealed that students' had different views on how feedback practice is best given (Altstaedter \& Doolittle, 2014; Enginarlar, 1993; Hyland, 2001; Nelson \& Carson, 1998; Tsui \& Ng, 2000) (see Section 2.3). It is still inconclusive whether noticing promoted through collaborative feedback (i.e., peer feedback together with teacher's scaffolding) in classroom practices is regarded by learners as providing powerful feedback for their learning. With this in mind, the present study was designed, aiming to introduce noticing-based collaborative feedback in a secondary classroom (i.e., 41 students) to explore whether such an approach exerts impacts on learners' beliefs. This study seeks answers to the following two research questions:

1). What are students' attitudes toward noticing-based collaborative feedback on their writing performance?

2). To what extent do students agree with using noticing techniques in the correcting process?

\section{Guidelines from Theoretical Resources}

\subsection{Noticing and (Collaborative) Feedback}

There is a strong consensus in the current literature that consciously attending to language input and output is vital in L2 learning (Robinson, 1995; Schmidt, 1990, 2001). Crucially important is the notion that feedback affects learning performance (Hattie \& Timperley, 2007). However, little classroom-based research has focused on promoting noticing through collaborative correction in EFL learners' writing output, especially in Vietnamese secondary classrooms. Although, two studies have addressed noticing through error correction by getting learners involved in comparing the initial writing with revisions (Qi \& Lapkin, 2001; Riddiford, 2006), many aspects of the process were unclear, such as the matter of how to engage learners with noticing/discovering the gaps, correcting those gaps, re-noticing the gaps and corrections, revising the first draft, and comparing the modified output with the initial writing. For this reason, this pilot study has attempted to incorporate noticing into collaborative feedback, taking these potential stages into consideration. In this section, the roles of noticing and feedback are described, followed by the ways they were used in the study, which this article reports.

Noticing, which is labelled variously as 'attention' or 'awareness' (Leow, 1997; Tomlin \& Villa, 1994) may be interpreted from two perspectives: psychological and educational. Psychologically, it is a kind of deliberate attention to features of one's language use or the phenomenon of paying attention to language input and output (Barnawi, 2010). Educationally, noticing may be construed as an aspect that teachers can exploit in boosting their students' independence and ability to identify the gaps between their interlanguage and the target language (Riddiford, 2006). Through this procedure, learners might experience an "affective interaction" before being exposed to aspects of a target language (Esimaje, 2012, p. 561). Noticing, being a conscious strategy and prerequisite for the occurrence of learning (ibid.), is important for the long-term memory storage of L2 information (Leow, 2007). According to Ellis (1995), noticing should be promoted through learning activities because he claims that if there is no noticing, then there is no acquisition. Given such a conscious condition of noticing, one might pose the questions: 'If a higher frequency of noticing occurs in the process of correcting, then what is the outcome of error correction?' and 'What are students' perceptions of noticing techniques?'.

Noticing as used in this study follows an implicitly guided procedure. Regarded as a technique of identifying or discovering errors referred to as gaps in this study, it moves from being teacher-guided to self-directed. For example, noticing takes place when teachers direct learners' attention to misused items in their writing output by questioning, searching, coding and other activities inherent in these tasks. Learners intentionally locate linguistic features, content, and organization to complete the tasks. Moreover, noticing is further operated when learners are occupied with the comparison between the initial drafts and their revisions.

Feedback plays a crucial role in L2 writing. Feedback is a form of information and negotiation between teacher and students or students and peers (Barnawi, 2010; Hattie \& Timperly, 2007). Being a message allowing comparison between a learning performance and a desired outcome, feedback can have various functions, including the identification and provision of specific information about learning, the purpose of the activities, and the learner's need (Mory, 2004).

Feedback is most effective when learners are provided with learning activities. Learning is operated when learners actively engage in noticing the gaps in their L2 performance, in examining interlanguage hypotheses, 
and in metalinguistic reflection (Van Beuningen, 2010). Moreover, they need to be offered an environment to assist with the corrective process and revise their writing (Ellis, 2009). Therefore, this project incorporated cognitive and social components throughout the process of discovering the gaps, correcting errors, revising the first draft, and comparing the modified output with the initial text.

Noticing through collaborative feedback (CF) can be implemented through three sequential and interrelated stages namely the pre-noticing, while-noticing, and post-noticing stages (Barnawi, 2010). The first phase instructs learners on the functions and the objectives of the feedback task. The second step focuses on contrastive-critical framing and transformed tasks. The final step is a procedure aimed at reflecting on what has been learnt in the previous stages. Being aware of the goal of the task in the initial step may facilitate the main processes because knowledge is absorbed through comprehension and reflection. Following Barnawi's (2010) recommendations, the study reported in this paper will utilise the three chronological and interconnected procedures comprising the noticing/discovering the gaps, collaboration-based correcting the errors, and consolidating and reflecting processes.

CF studies provide positive evidence regarding learning achievement. CF may be especially useful since it not only encourages learner autonomy and critical thinking (Yang et al., 2006) but also enhances learning thanks to learners' engagement with language. Svalberg (2009) argues that engagement is "the place where learning happens" (p. 243). Importantly, CF promotes argument, explanation, clarification, negotiation, and scaffolds these (Ellis, 2003; Rollinson, 2005; Storch, 2001). Moreover, it is important to require "learners' awareness of cognitive and social factors, which the teachers have understood to mean providing relevant topics, encouraging peer correction, and incorporating group activities of various kinds" (Hyland, 2009, p. 79). Collaborative activities are efficient since learners' noticing and verbalization increases, and thus metacognitive processes are engaged (Qi \& Lapkin, 2001). In summary, CF can activate learning if learners have more opportunities to interact with each other to give and respond to feedback on their writing. Therefore, the study presented in this paper will attempt to get the students involved in noticing and correcting errors through various activities (i.e., group work) to strengthen their cognitive and social awareness.

$\mathrm{CF}$, therefore, involves joint efforts among groups and between teachers and students (Barnawi, 2010) and the mutual engagement of learners in an integrated effort to accomplish a task (Min, 2006). Accordingly, CF of this study is interpreted as reciprocal work between students and peers or students and teachers who have mutual support in exchanging, negotiating, interpreting and arguing ideas. It is supposed that through the process of intervention, learners may learn by doing, and thus the power of CF may be strengthened and the teacher's authority in the classrooms may be reduced. Collaborative learning is elaborated in the next section.

\subsection{Collaborative Learning (CL)}

In this section, an explanation of the theoretical principles of CL and its implementation in this study is presented. It is important to have a closer look at the nature of CL, the objectives, principles, and effects of CL in language teaching. CL is regarded as cooperative learning, group-based learning or learning together, and has received considerable interest of educators (Ellis, 2003; Jacobs, McCafferty, \& Iddings, 2006; Johnson, Johnson, \& Smith, 1998; Richards, 2006). The target of collaboration is both "to get everyone to think alike" and "to get everyone to share and to develop" their individual thoughts through engaging procedures (Jacobs et al., 2006, p. 16). Additionally, the key constructs of collaboration are positive interdependence, individual accountability, promotive interaction, socialization, and group processing (Jacobs et al., 2006; Johnson et al., 1998, \& Kohonen, 1992).

Of the five principles highlighted by Johnson et al., (1998), Kohonen (1992), and Richards (2006), this project implemented four concepts elaborated as follows. First, positive interdependence is considered as a sense of support and cooperation in which learners "sink or swim together" to achieve a mutual learning goal (Johnson et al., 1998, p. 30). Second, individual accountability is harnessed to make an individual a stronger group member as their individual performance is contributed. The third element is group interaction referred to as verbal face-to-face negotiation to promote each other's success by offering aid, encouragement, and praise. Fourth, social skills entail the explicit instruction of several strategies, namely leadership, decision-making, communication, trust and conflict-resolution skills for the group to progress appropriately.

The principles of forming and operating groups, designing activity, and teacher collaboration are considered. Such major factors are illustrated to build up the effects of CL (Ellis, 2003; Jacobs, 2006). Groups in this study were constructed with some level of heterogeneity (i.e., four students) (Jacobs, 2006; Kohonen, 1992). When working in different-ability groups, fast learners can have solid consolidations of their understanding when explaining the issues to slower learners, and thus peer-tutoring may be beneficial to multiple-ability students. For 
example, if highly capable learners offer solutions to treat errors, low-ability learners probably learn the ideas provided and are motivated by peers, just as those offering solutions are deepening their own knowledge and awareness. In this way, positive interdependency is established due to each member's endeavour and care about mutual learning.

Students were also equipped with some collaborative skills which they had not experienced. Such skills included saying thank-you, asking for clarification, and praising a teammate's good work (see also Wee \& Jacobs, 2006). This formal training of learning skills has been encouraged by previous researchers (Johnson et al., 1998; Nunan, 1992). Moreover, to enrich and extend interaction, the "Stay-Stray" grouping strategy was instructed (Kagan, 1992 cited in Jacobs, 2006, p. 193). First, each individual in a group was advised to hold a number (i.e., 1, 2, 3, 4). Then, groups completed the correction tasks. Upon completion, three members left the group and strayed individually to other groups according to their number (i.e., 1 with 1). Stayers shared the ideas that their groups had discussed with the visiting strayers and in turn strayers asked questions for clarification. After that strayers came back to their home group and reported what they had learnt, whereas the stayers talked about the feedback they received from the visiting strayers. Finally, groups revised their original papers.

\subsection{Learners' Perspectives on Written Corrective Feedback}

Research has indicated that feedback strategy is an indispensable stage in writing instruction. There is strong evidence in the research literature of the impact of feedback on students' motivation to give and respond to feedback as examined through their perspectives on the collaboration of peers and teacher and on peer comments (Enginarlar, 1993; Nelson \& Carson, 1998; Tsui \& Ng, 2000). Nevertheless, students' attitudes toward feedback (i.e., from teacher and peers) have shown different stances. The study reported in this paper is related to previous studies regarding the feedback tactic and learners' attitudes. However, the combination of peer feedback and the teacher's scaffolding were fostered through the cycle of learning tasks and comments on both global and local aspects (i.e., linguistic features, content, \& organization). Additionally, attentional resources of noticing were utilised during the correcting process.

Enginarlar (1993) examined 47 EFL students' reflection on teacher feedback using closed-ended and open-ended questionnaires. This study employed two main stages: (1) signalling of linguistic gaps with codes (i.e., coded feedback), and (2) a range of concise feedback points to enhance the quality of the first draft. Students' qualitative responses indicated that they preferred the utility and value of the potential feedback. Also, they highly valued the revised task as a type of collaboration shared by students and the teacher. Quantitative data revealed "different student orientations to teacher feedback in revision work" (p. 193).

An investigation of students' perspectives on their interactions in peer response was carried out by Nelson and Carson (1998). The analysis of the videotapes and the interviews revealed that learners (i.e., Chinese \& Spanish) preferred negative comments; a particularly favoured option was the teacher's feedback over that of peers. Also, they perceived that comments on grammar and sentence-level were unhelpful and expressed different views on the efficacy of peer comments in terms of cultural differences. Students' explanation for preferring teacher's feedback was their belief that the teacher was the expert because they claimed that peers spent a great deal of time discussing irrelevant issues. Based on students' claims, one might question "what would happen if peers were directed to be occupied with specific tasks in correcting errors?".

Another example of research that supports students' perceptions of teacher and peer feedback is the study of Tsui and $\mathrm{Ng}$ (2000). The participants were 27 Chinese students (i.e., Grades $12 \& 13$ ) in a secondary school in Hong Kong where English is used as a medium of instruction. The questionnaire results showed that teacher comments were highly valued over peer comments, and that teacher feedback was directed more towards revision than that of peers. This is because they viewed the teacher as a stereotype of authority that guaranteed quality. Yet, the analysis of the semi-structured interviews displayed an acknowledgement of the positive contribution to the writing process of peer feedback, which was identified by responses regarding four roles of peer feedback. In particular, peer feedback: (1) fostered students' sense of audience; (2) enhanced students' awareness of giving and responding to feedback; (3) promoted collaborative learning; and (4) encouraged a sense of text ownership. It is, therefore, suggested that peer feedback plays a crucial part in learning no matter what proficiency level second language learners have.

In a 10-month study exploring perspectives of distance learners and of tutors on feedback, Hyland (2001) employed feedback focusing on the product and on the learning process. The former included content, organization, accuracy, and presentations while the latter prioritized encouragement, reinforcement of materials, and suggestions to enhance the learning process. It was discovered from the analysis of text, questionnaire, and interviews that the differences between individuals are noticeable in their attitudes to the feedback provided by 
the tutors and there was a variation in the type of feedback students wanted to be offered and the implementation of it. Learners rated feedback highly when it pertained to comments on grammar, organization, content and ideas and considered their tutor's role as a facilitator, showing them the locations of their overall strengths and limitations. Furthermore, the tutors perceived that feedback served a crucial role in a distance-learning setting, fostering and promoting students although they were unsure whether feedback improved students' learning performance.

More recently, the impact of feedback on learning and teaching as measured through learners' perceptions has been addressed (Poulos \& Mahony, 2008). Poulos and Mahony (2008) explored students' perceptions of the influence of feedback on the learning and teaching process. They thematically analysed three dimensions: attitudes toward feedback, impact of feedback, and credibility of feedback. The analysis of the perception of feedback revealed that students were more in favour of specific rather than general feedback. The term general feedback, referred to as feedback provided for the whole class, was not felt to be well connected to individual learners. Additionally, the effect and credibility of feedback varied according to the way it was provided (i.e., types of delivery) and timeliness, and thus they concluded that "the impact of feedback is influenced by student perceptions of the provider" (p. 153).

Altstaedter and Doolittle (2014) explored students' perceptions of peer feedback. Sixty-five intermediate Spanish college students responded to close-ended and open-ended questions. Quantitative responses showed that students had more positive attitudes toward receiving peer written comments than reading their partner's writing and receiving their partner's face-to-face peer feedback. Additionally, qualitative responses revealed that students received more global elements such as comments on organization and idea development than local components including comments on grammar and mechanics.

There is a strong consensus in the previous studies that peer feedback (Nelson \& Carson, 1998; Tsui \& Ng, 2000; Altstaedter \& Doolittle, 2014) and teacher/tutor feedback (Enginarlar, 1993; Hyland, 2001) are practical variables that can be incorporated into writing instruction. For instance, peer feedback enables students to improve the quality of writing based on global aspects which include awareness of audience, of their own gaps in writing, of group discussion and interaction, and of text ownership. However, it is worth noting that students may consider that comments from peers on the 'local aspect' of grammar and sentence-level language are ineffective (Nelson \& Carson, 1998). As such, there is an important need for the present feedback research, for instance, to link both global and local aspects of writing to strengthen the quality of feedback. Also important are cultural differences and various corrective strategies, which may influence learners' expectations on feedback under different circumstances.

\subsection{Collaborative Feedback Framed by Sociocultural Theory}

One of the L2 teaching and learning theories connected to cooperative learning is sociocultural theory originating from the work of Vygotsky (Jacobs \& McCafferty, 2006). According to sociocultural perspectives, the development of L2 is through mediating and internalizing processes (Lantolf, 2006; Lantolf \& Thorne, 2007). This concept sees language competence as being constructed through social interaction such as mutual problem solving and discussion (Ellis, 2008; Mitchell \& Myles, 2004). Constructed by sociocultural views, corrective feedback is seen as a conductive channel for SLA since it fosters noticing, triggers modifications of output, and enhances the achievement of individual regulation through mutual cooperation (Pawlak, 2013).

The improvement of language takes place when interaction enables learners to construct a "Zone of Proximal development" that moves them from mutual to individual efforts (Ellis, 2008). For example, scaffolding from peers or teacher may enable low level learners to comprehend and perform a language feature confidently, without which learners would face a number of difficulties (Shen \& Ellis, 2011). In accordance with CL, sociocultural theory emphasizes social learning by means of interaction in cultural and historical situations. Thus, learners utilize individual and joint efforts to make L2 learning accessible (Jacobs \& McCafferty, 2006).

The CF used in this study moved from mutual learning experiences to individual learning, with the aim to facilitate self-comprehension through CL activities. The main channels including peers' input, the assistance from the teacher and peers, feedback guide, and training were used to scaffold learners' efforts in treating errors. Additionally, various techniques comprising note-taking and sorting activities were designed to link group efforts with personal impact, each individual was encouraged to complete their own tasks based on group discussion. Importantly, the major principles of CL such as positive interdependence, individual accountability, and group interaction were implemented. From social perspectives CF can, therefore, play a crucial role in learning because it places emphasis on a scaffolding position within which less proficient students can receive input from more knowledgeable agents (i.e., teacher or peer) (Wigglesworth \& Storch, 2012). 


\section{Method}

\subsection{Participants}

Forty-one high school students aged 17 (mixed genders) whose English levels were pre-intermediate participated in the study. The participants were Grade-11 students who had spent six years learning English as a compulsory subject. The teacher participant was a male teacher who had 5 years of experience in teaching English as a foreign language at Marie Curie high school in Ho Chi Minh City, Vietnam.

The students and the teacher were invited to participate in a four-week collaborative correcting intervention for two reasons. First, the researcher used the instructional treatment and the questionnaire as a pilot procedure for an ongoing study in the same context. Second, upon completion of the piloting process, the researcher would have specific information to amend the corrective practices and the instrument if needed.

\subsection{Procedure and Instrumentation}

Although the study had two phases comprising the cooperative writing and the collaborative correction treatment (i.e., group work), the main focus was on identifying the extent to which students reacted to feedback practice by their responses to the five-point Likert Scale questionnaire categorised into the themes of approach preference, proficiency of correcting and accurate writing, the effects of collaborative correction and of teacher correction, and the potential of noticing techniques.

Phase 1: Groups of students wrote two letters and two descriptions (i.e., curriculum-based) including a letter of invitation and a letter to respond to the invitation and the descriptions of a best friend and of a memorable experience.

Phase 2: Drawing on students' writing output, collaborative feedback treatment was conducted.

The procedures of the collaborative error treatment were designed through the cycle of a learning task, namely, pre-task, task-performance, and post-task. A learning task of this study was regarded as a solving task (i.e., finding solutions to treat errors) promoting learners' engagement with correction. Accordingly, the specific objective was to provide better procedures for language learning to occur (Richards \& Rodgers, 2001). All in all, $\mathrm{CF}$ is referred to as a meaningful-interactive practice incorporating a focus on both form and communication of meaning in the application of task components.

Error correction tasks, after all, cannot be detached from the approach of instruction that supports them pedagogically. In order to facilitate a collaboration-based corrective process, correcting errors was designed to be output-driven in which scaffolding such as peers' input, a feedback guide, the teacher's assistance, and training was used as the main means to tackle learning difficulties. Thus, following the notions of Richards and Rodgers (2001), language was expected to emerge in the meaningful and authentic practices (i.e., input \& output) in which mutual learning was constructed and learners were exposed to the emergence of learning activities encouraging partnership and collaboration.

The process of correcting was divided into three stages: pre-correcting, while-correcting, and post-correcting.

Pre-correcting: The first stage involves noticing or discovering the gaps. Groups of students were delivered the same writing output and received implicit instruction to discover gaps. Students were first guided to locate and identify linguistic features, content, and organization. Noticing activities were questioning, coding and underlining. Some examples were: (1) Can you find lexical errors in line two paragraph one? (2) Is there a topic sentence in the first paragraph? (3) Specify the error related to tense (T) in line two paragraph one.

While-correcting: The second stage is regarded as a collaborative correcting practice. Individuals of groups of students were administered a collaborative feedback guide to take notes and to collate errors under appropriate categories. Students interacted with each other to treat errors based on the CF guide and group-work activities. The collaborative correction was accomplished through "interrelated feedback" such as "contrastive-critical framing" (Barnawi, 2010, p. 213) with the teacher's support. The students then performed some output activities including note-taking and sorting tasks to cooperatively re-check the errors, classify and put them into the correct error column. Finally, learners transformed their corrected writing for the other group to re-notice the gaps and to check their corrections by "transformed practice" (Barnawi, 2010, p. 213).

Post-correcting: The final stage involves a consolidating and reflecting process. Groups revised the first draft and compared the modified output with the first draft.

There were two sections in the questionnaires. Section 1 consisting of five questions referring to attitudes toward the newly implemented error treatment compared to the teacher correction through which students had normally learnt prior to the intervention. The first question asked about their approach preference (Theme 1, see Table 1). 
Questions 2 and 3 aimed to select students' beliefs about the proficiency of correcting errors and accurate writing (Theme 2, see Table 1). The next two questions (4-5), each of which included six statements (Theme 3, see Table 2) explored the effects of $\mathrm{CF}$ and teacher correction.

Section 2 elicited students' reaction to noticing activities separated into five categories (Theme 4, see Table 3 )

\section{Findings and Discussion}

\section{Focus of Research Question 1: Attitudes toward noticing-based collaborative feedback}

Theme 1: Approach preference (see Table 1)

The students $(\mathrm{N}=41)$ were absolutely positive about collaborative feedback. The fact that most learners $(71 \%$; $\mathrm{n}=29$ ) had positive attitudes toward collaborative correction compared to those who had a preference for the teacher's direct correction $(26 \% ; n=11)$, and $(2 \% ; n=1)$ preferred self-correction, confirms what was outlined above regarding the benefits of $\mathrm{CF}$ which enable learners to have more opportunities to share ideas, explanation, clarification, negotiation, and scaffold each other other's learning (see Ellis, 2003; Rollinson, 2005; Storch, 2001). This may be explained as demonstrating that the more chances fast students had in tutoring peers, the higher the level of consolidation they got, and, vice versa, that low-ability learners might have learnt the ideas offered by peers (see Jacobs, 2006; Kohonen, 1992). This is also supported by the results of previous studies indicating that students preferred cooperative correction (Altstaedter \& Doolittle, 2014; Enginarlar, 1993; Tsui \& $\mathrm{Ng}$, 2000). Consequently, positive interdependency was built thanks to each individual's endeavour.

Interestingly, eight students specified briefly that they liked collaborative correction because (1) the correcting tasks were specific, relevant to their proficiency level, and negotiable, and (2) the higher the participation among group members, the more likely that the collaborative process would create interest. Thus, it can be stated that to a certain extent individual responsibility was not highly promoted although students considered the tasks beneficial. This was supported by the impact of specific kinds of feedback and feedback affected by student attitudes toward the feedback provider, found in the study of Poulos and Mahony (2008). Consequently, it is important for teachers to pay more attention to collaborative strategies to enhance the quality of cooperation shared among individuals.

However, the students' responses to the questionnaire about the beneficial effects of CF were divided. It is worth noting that although 71 percent of students preferred CF, the balance of opinion differed in relation to correction; the number of students choosing the benefits of collaborative correction $56 \%$ of 41 in this case compared to those preferring teacher correction $(44 \%, \mathrm{n}=41)$. This may be interpreted as indicating that during group interaction to treat errors, students had to consider many options while if treated by teacher's correction, there would be an obvious and clear explanation and correction. Also, this response may be accounted for by the dependent learning styles and the traditional beliefs in the teacher-oriented authority of students in this context (Nelson \& Carson, 1998; Tuan, 2010). That is likely to be $44 \%$ of students agreed with the beneficial effects of the teacher's direct correction

Themes 2 and 3: Proficiency of correcting and accurate writing (see Table 1)

Table 1. Approach preference \& proficiency

\begin{tabular}{|c|c|c|c|c|c|c|c|c|c|c|}
\hline \multirow[t]{2}{*}{ Theme } & \multicolumn{2}{|c|}{$\begin{array}{l}\text { Small } \\
\text { group }\end{array}$} & \multicolumn{2}{|c|}{$\begin{array}{l}\text { Group \& teacher's } \\
\text { assistance }\end{array}$} & \multicolumn{2}{|c|}{$\begin{array}{l}\mathrm{N}=41 \\
\text { Paris }\end{array}$} & \multicolumn{2}{|c|}{$\begin{array}{l}\text { Teacher's direct } \\
\text { correction }\end{array}$} & \multicolumn{2}{|c|}{$\begin{array}{l}\text { Myself } \\
\text { (individually) }\end{array}$} \\
\hline & $\mathrm{N}$ & $\%$ & $\mathrm{~N}$ & $\%$ & $\mathrm{~N}$ & $\%$ & $\mathrm{~N}$ & $\%$ & $\mathrm{~N}$ & $\%$ \\
\hline \multirow[t]{2}{*}{ Q1. Approach preference } & 6 & 14.63 & 18 & 43.9 & 5 & 12.2 & 11 & 26.38 & 1 & 2.44 \\
\hline & & Poor & \multicolumn{2}{|c|}{ Not so poor } & \multicolumn{2}{|c|}{ Good } & \multicolumn{2}{|c|}{ Very good } & \multicolumn{2}{|c|}{ Excellent } \\
\hline $\begin{array}{l}\text { Q2. Proficiency of } \\
\text { correcting ability }\end{array}$ & 2 & 4.88 & 10 & 24.39 & 17 & 41.46 & 12 & 29.27 & 0 & 0 \\
\hline $\begin{array}{l}\text { Q3. Prociency of accurate } \\
\text { writing performance }\end{array}$ & 2 & 4.88 & 5 & 12.2 & 20 & 48.78 & 13 & 31.71 & 1 & 2.44 \\
\hline
\end{tabular}

Overall the respondents perceived that $\mathrm{CF}$ led to improvement. About two thirds of learners $(71 \% ; n=41)$ strongly agreed and agreed that collaborative correction enabled them to enhance their ability to correct errors. Remarkably, a large number of learners (83\%) showed their strong agreement that CF did affect their accurate 
writing performance in their revisions. These views confirm what Barnawi (2010), Hattie and Timperly (2007), and Hyland and Hyland (2006) stated regarding the potential of CF in writing. Further, the findings were supported by those of the previous studies (Bitchener, 2008; Chandler, 2003; Diab, 2011; Lopez-Serrano et al., 2010; Rassaei, 2013; Shintani \& Ellis, 2013). Thus, it may be stated that the higher the frequency of scaffolding and interdependence students experienced, the better the outcomes were; indeed, the main agents of the learning process saw such feedback practice as leading to improvement.

Themes 4 and 5: Benefits of teacher and collaborative correction (see Table 2)

Table 2. Benefits of teacher and collaborative correction

\begin{tabular}{|c|c|c|c|c|c|c|c|c|c|c|}
\hline \multirow{3}{*}{$\begin{array}{l}\text { Theme } \\
\text { Q4. Benefits of } \\
\text { collaborative correction }\end{array}$} & \multicolumn{2}{|c|}{$\begin{array}{l}\text { Strongly } \\
\text { Agree }\end{array}$} & \multicolumn{2}{|c|}{ Agree } & \multicolumn{2}{|c|}{ Neutral } & \multicolumn{2}{|c|}{ Disagree } & \multicolumn{2}{|c|}{$\begin{array}{l}\text { Strongly } \\
\text { Disagree }\end{array}$} \\
\hline & \multirow[b]{2}{*}{$\mathrm{N}$} & \multirow[b]{2}{*}{$\%$} & \multirow[b]{2}{*}{$\mathrm{N}$} & \multirow[b]{2}{*}{$\%$} & \multicolumn{2}{|c|}{$\mathrm{N}=23$} & \multirow[b]{2}{*}{$\mathrm{N}$} & \multirow[b]{2}{*}{$\%$} & \multirow[b]{2}{*}{$\mathrm{N}$} & \multirow[b]{2}{*}{$\%$} \\
\hline & & & & & $\mathrm{N}$ & $\%$ & & & & \\
\hline A. Sharing ideas & 11 & 47.83 & 10 & 43.48 & 2 & 8.7 & 0 & & 0 & \\
\hline B. Fruitful solutions & 12 & 52.17 & 11 & 47.83 & 0 & & 0 & & 0 & \\
\hline C. Active engagement & 11 & 47.83 & 10 & 43.48 & 2 & 8.7 & 0 & & 0 & \\
\hline $\begin{array}{l}\text { D. Frequency of } \\
\text { correction }\end{array}$ & 12 & 52.17 & 8 & 34.78 & 3 & 13.4 & 0 & & 0 & \\
\hline $\begin{array}{l}\text { E. Enjoyment \& } \\
\text { motivation }\end{array}$ & 12 & 52.17 & 8 & 34.78 & 3 & 13.4 & 0 & & 0 & \\
\hline F. Mutual support & 12 & 52.17 & 10 & 43.48 & 1 & 4.35 & 0 & & 0 & \\
\hline $\begin{array}{l}\text { Q5. Benefits of teacher } \\
\text { correction }\end{array}$ & & & & & $\mathrm{N}=$ & & & & & \\
\hline $\begin{array}{l}\text { A. Effective use of } \\
\text { language }\end{array}$ & 8 & 44.44 & 9 & 50 & 0 & & 0 & & 1 & 5.56 \\
\hline B. Easy to understand & 10 & 55.56 & 8 & 44.44 & 0 & & 0 & & 0 & \\
\hline $\begin{array}{l}\text { C. Fast solutions to treat } \\
\text { errors }\end{array}$ & 7 & 38.89 & 6 & 33.33 & 3 & 16.67 & 1 & 5.56 & 1 & 5.56 \\
\hline D. High reliability & 10 & 55.56 & 6 & 33.33 & 1 & 5.56 & 0 & & 1 & 5.56 \\
\hline E. High concentration & 10 & 55.56 & 6 & 33.33 & 1 & 5.56 & 0 & & 1 & 5.56 \\
\hline F. Clear explanation & 7 & 38.89 & 10 & 55.56 & 0 & & 0 & & 1 & 5.56 \\
\hline
\end{tabular}

The total number of students $(\mathrm{n}=41)$ who responded to the items about the particular approach they preferred was divided into two groups; a positive group $(56 \% ; n=41)$ and a negative group $(44 \% ; n=41)$. To be specific, the positive group $(n=23)$ was the group who chose to respond only to the advantages of collaborative correction while the negative group $(n=18)$ was the group selecting the benefits of teacher correction.

The participants' responses to the effects of CF were separated. It is worth mentioning that while most learners $(71 \%, n=41)$ preferred collaborative correction, their attitudes toward the collaborative effects were split $(56 \%$ vs $44 \%)$. This reality may have been caused by a strong belief in the value of the teacher's correction over peer correction (Nelson \& Carson, 1998). The positive students $(\mathrm{n}=23)$ agreed that collaborative correction did lead to positive learning outcomes, and this view may be further elaborated and interpreted.

In particular, a large number of 'positive' students $91 \%$ and $100 \%$ of 23 in this case strongly opined that they had more opportunities to share ideas to treat errors and that group interaction offered a variety of solutions to correct errors during the correcting process. Such results were apparent in the previous studies focusing on the benefit of mutual learning (Altstaedter \& Doolittle, 2014; Tsui \& Ng, 2000). More importantly, a large number of these 
positive respondents (87\%-95\%) were overwhelmingly positive towards the impact of collaborative correction on active engagement, frequency of correction, a joyful and motivated ecology, and mutual support. These may have resulted from the opportunities to use multiple types of intelligences through interacting, discussing, associating, and scaffolding between high achievers and low achievers (Jacobs, 2006; Kohonen, 1992). In sum, these students might have benefited from various forms of scaffolding such as the assistance from the teacher and peers, peers' input, the feedback guide, and training. All acted as supportive agents assisting individual and mutual efforts to facilitate learning (Jacobs \& McCafferty, 2006) and through mutual cooperation, noticing was fostered and writing output was modified.

The negative respondents $(n=18)$, on the other hand, displayed their preferences for the teacher's direct correction, however, their perceptions of the statements also represented neutral and disagreed points (see Table 2). Particularly, the degree of positive agreement varied from $72 \%$ to $100 \%$ : $91 \%$ agreed on the efficient use of language offered, $100 \%$ on comprehensibility, about $72 \%$ on the speed of solutions, $89 \%$ on high concentration, and $94 \%$ on clear explanation. The high ratios of consensus about the effectiveness of the teacher's feedback confirm what was found in the previous studies (Hyland, 2001; Nelson \& Carson, 1998); feedback in both global and local aspects such as comments on grammatical errors and those on content and ideas were the options given the strongest preference.

Focus on Research Question 2: Attitudes toward noticing activities

Theme 6: Benefits of noticing activities (see Table 3)

Table 3. Attitudes toward noticing activities

\begin{tabular}{|c|c|c|c|c|c|c|c|c|c|c|}
\hline \multirow{2}{*}{$\begin{array}{l}\text { Theme } \\
\text { Q6. Benefits of } \\
\text { noticing strategies }\end{array}$} & \multicolumn{2}{|c|}{$\begin{array}{l}\text { Strongly } \\
\text { Agree }\end{array}$} & \multicolumn{2}{|c|}{ Agree } & \multicolumn{2}{|c|}{$\begin{array}{l}\mathrm{N}=41 \\
\text { Neutral }\end{array}$} & \multicolumn{2}{|c|}{ Disagree } & \multicolumn{2}{|c|}{$\begin{array}{l}\text { Strongly } \\
\text { Disagree }\end{array}$} \\
\hline & $\mathrm{N}$ & $\%$ & $\mathrm{~N}$ & $\%$ & $\mathrm{~N}$ & $\%$ & $\mathrm{~N}$ & $\%$ & $\mathrm{~N}$ & $\%$ \\
\hline $\begin{array}{l}\text { A. Easy to discover } \\
\text { errors }\end{array}$ & 8 & 19.51 & 20 & 48.78 & 12 & 29.27 & 0 & 0 & 1 & 2.44 \\
\hline $\begin{array}{l}\text { B. High frequency of } \\
\text { notice and re-notice } \\
\text { the gaps }\end{array}$ & 12 & 29.27 & 20 & 48.78 & 8 & 19.51 & 0 & 0 & 1 & 2.44 \\
\hline $\begin{array}{l}\text { C. Facilitation of } \\
\text { comprehension of } \\
\text { language use }\end{array}$ & 12 & 29.27 & 23 & 56.1 & 5 & 12.2 & 0 & 0 & 1 & 2.44 \\
\hline $\begin{array}{l}\text { D. Fostering curiosity } \\
\text { and engagement with } \\
\text { feedback }\end{array}$ & 6 & 14.63 & 23 & 56.1 & 7 & 17.07 & 4 & 9.76 & 1 & 2.44 \\
\hline $\begin{array}{l}\text { E. Discovering } \\
\text { strengths and } \\
\text { weaknesses }\end{array}$ & 12 & 29.27 & 23 & 56.1 & 3 & 7.32 & 2 & 4.88 & 1 & 2.44 \\
\hline
\end{tabular}

As explained above, noticing was used as a means to discover the gaps and to re-notice the errors and the corrections in the revised writing. Students' perceptions of noticing activities were not as overwhelmingly positive as those of the effectiveness of collaborative feedback. For instance, the levels of concord regarding noticing tasks varied from $68 \%$ to $85 \%$ compared to the variation of $72 \%$ to $100 \%$ of those on the potential of collaborative feedback. In particular, $68 \%$ of students perceived that implicit instruction to discover the gaps facilitated them to notice the errors. Furthermore, a higher percentage of respondents (78\%) saw note-taking and sorting activities as helping them increase the ability to notice and re-notice the gaps in their writing, and thus re-notice errors. The corrections provided by peers fostered the awareness of language use in an authentic context and increased the discovery of the strengths and weaknesses of their papers; these views accorded $85 \%$ agreement. More importantly, most learners $(70 \%)$ expressed their strong beliefs that noticing activities in the pre-correcting stage promoted their curiosity and engagement with error correction.

There is clear evidence in the literature that noticing is a valuable component in language instruction since it 
facilitates learning on two levels including the level of noticing and the level of understanding (Schmidt, 1990; 2001). To a greater or lesser extent, the students in this study might have absorbed the two levels of noticing in some possible stages. First, they seemed to have engaged in or attended to discovering the gaps in their papers in the pre-correcting stage. Then, noticing was operationalized in a higher level referred to as a reflective stage; that was re-noticing the gaps and the corrections of those gaps in the while-correcting process. Finally, noticing was promoted through the level of comprehension because learners were involved in the comparison between their original drafts and their revised papers, which Ellis (1995) refers to as "cognitive comparison" (p. 90). It is necessary to take into consideration that learners' perspectives on the value of noticing in the correcting process may affect the correcting outcome. The analysis of the questionnaire suggested that students strongly perceived that noticing was beneficial, confirming the importance of the attentional resources of noticing such as alerting, orienting, and detecting (Robinson, 1995), and that noticing was promoted through a conscious and cognitive process of correcting errors. It also illustrates what Schmidt (2001) has claimed that learners can learn about the things they consciously pay attention to. Thus, noticing might be triggered through collaborative feedback in drawing learners' attention to language use in their writing output and their revised papers.

\section{Implications and Conclusions}

As mentioned above, the scope of the study was to have the experimental teaching and the questionnaire pilot-tested, thus there may be certain limitations in terms of the single form of data, the experimental duration, and the sampling. Nevertheless, the implications drawn from this study may be relevant for similar EFL settings and such implications may play crucial roles in an ongoing study which focuses on the main tenets of scaffolding shaped by sociocultural theory such as the ways the frequency of interaction and engagement affect learning.

The reciprocal correcting tactics were operationalized such that individual cooperation was connected within a mutually exploratory and supportive setting. For instance, the students were provided with different kinds of activities to discover errors, to negotiate and discuss how to treat the errors, to revise their own writing output, and to compare the initial drafts with their revisions. To a certain extent social learning occurred in a specific setting in which learners were the main agents who scaffolded each other's contributions and considered their own options and appropriate solutions to correct the errors and edit their writing. It is, therefore, suggested that CF is congruent with student expectations, which are represented by their comment "I preferred the tasks because of their specificity, relevance, and negotiation". Thus, it may be concluded that learners had opportunities to clarify and explain their ideas and collaboratively discover efficient ways to treat errors in this process-oriented approach. As a consequence, learners might be actors and observers of their own learning processes (Nunan, 1992) and create a high sense of support and cooperation (Jacobs, 2006; Johnson et al., 1998). In this way, the knowledge was built upon the incorporation of noticing, interaction, and written correction through this collaborative correcting process and CF was thus likely to establish multiple-way responses within which negotiations can be manipulated among members.

The project may make contributions to the discourse of promoting the quality of instruction on correcting errors instruction thanks to the advent of the collaborative classroom setting. The highly positive concurrence with the value of noticing-based collaborative feedback implies that this potential approach might equip students with the experience of mutual learning within which peers' input, the teacher's assistance, and the feedback guide would be intertwined to tackle learning difficulties. In essence, this is the shift from an individualized learning context in which the teacher is the unique source to provide knowledge to a collaborative learning setting where the contributions among peers and teacher are integrated. Specifically, the experience of the shift from the writer to the reader and the editor might reinforce learner autonomy and competence of using language. Accordingly, students' viewpoints on their habitual learning style labelled as 'being fed' by teachers might be positively shifted. More importantly, learners might be more creative to discover/improve their own learning style rather than being given uniform language exercises to practice individually. In sum, the collaborative manipulation of the text ownership might enable learners to control their own learning process and to find out their strengths and weaknesses as language users thanks to the teacher's involvement in exchanging and contributing ideas.

It is, however, acknowledged that students' responses to themes related to the framework of discourse regarding the power of feedback and learners' reactions raise some concerns. The division attitudes towards the effectiveness of collaborative feedback suggest a key challenge for teachers to modify corrective strategies to suit all levels of proficiency and enhance the quality of feedback. In addition, students' desire to have higher participation among group members asserts that students need more and specific training in how to collaborate effectively to foster individual interdependency and to care about mutual learning. It is, therefore, suggested that teachers should be aware of student expectations and reactions to feedback practice, which feed back to teachers to help them reassure such collaborative feedback is qualified and highly congruent with student wish. 


\section{References}

Altstaedter, L. L., \& Doolittle, P. (2014). Students' perceptions of peer feedback. Argentinian Journal of Applied Linguistic, 2(2), 60-76.

Barnawi, O. Z. (2010). Promoting noticing through collaborative feedback tasks in EFL college writing classrooms. International Journal of Teaching and Learning in Higher Education, 22(2), 209-217.

Bitchener, J. (2008). Evidence in support of written corrective feedback. Journal of Second Language Writing, 17(2), 102-118. http://dx.doi.org/10.1016/j.jslw.2007.11.004

Chandler, J. (2003). The efficacy of various kinds of error feedback for improvement in the accuracy and fluency of student writing. Journal of Second Language Writing, 12(3), 267-96. http://dx.doi.org/10.1016/S1060-3743(03)00038-9

Diab, N. M. (2011). Assessing the relationship between different types of student feedback and the quality of revised writing. Assessing Writing, 16, 274-292. http://dx.doi.org/10.1016/j.asw.2011.08.001

Ellis, R. (1995). Interpretation tasks for grammar teaching. TESOL Quarterly, 87-105. http://dx.doi.org/10.2307/3587806

Ellis, R. (2003). Task-based language learning and teaching. Oxford: Oxford University Press.

Ellis, R. (2008). Study of second language acquisition (2nd ed.). Oxford: Oxford University Press.

Ellis, R. (2009). Corrective feedback and teacher development. L2 Journal, 1, 3-18.

Enginarlar, H. (1993). Student response to teacher feedback in EFL writing. System, 21(2), 193-204. http://dx.doi.org/10.1016/0346-251X(93)90041-E

Esimaje, A. U. (2012). Teaching English as a second language: The role of noticing the gap. Theory and Practice in Language Studies, 2(3), 560-565. http://dx.doi.org/10.4304/tpls.2.3.560-565

Ferris, D. R. (2011). Treatment of error in second language student writing. United States of America: University of Michigan.

Hattie, J., \& Timperley, H. (2007). The power of feedback. Review of Educational Research, 77(1), 81-112. http://dx.doi.org/10.3102/003465430298487

Hyland , F. (2001). Providing effective support: Investigating feedback to distance language learners. Open Learning, 16(3), 233-247. http://dx.doi.org/10.1080/02680510120084959

Hyland, K., \& Hyland, F. (2006). Feedback in second language students' writing. Language Teaching, 39(02), 83-101. http://dx.doi.org/10.1017/S0261444806003399

Hyland, K., \& Hyland, F. (2006). Contexts and issues in feedback on L2 writing: An introduction. In K. Hyland, \& F. Hyland (Eds.), Feedback in second language writing: Contexts and issues (pp. 1-18). Cambridge, UK.: Cambridge University Press.

Hyland, K. (2009). Teaching and researching writing. United Kingdom: Longman.

Jacobs, G. M. (2006). Cooperative learning techniques and activities. In S. G. McCafferty, G. M. Jacobs, \& C. Iddings (Eds.), Cooperative learning and second language teaching (pp. 181-196). New York: Cambridge University Press. http://dx.doi.org/10.1017/CBO9781139524742

Jacobs, G. M., \& McCafferty, S. G. (2006). Connections between cooperative learning and second language learning and teaching. In S. G. McCafferty, G. M. Jacobs, \& C. Iddings (Eds.), Cooperative learning and second language teaching (pp. 18-29). New York: Cambridge University Press.

Jacobs, G. M., McCafferty, S. G., \& Iddings, C. (2006). Roots of cooperative learning in general education. In S. G. McCafferty, G. M. Jacobs, \& C. Iddings (Eds.), Cooperative learning and second language teaching (pp. 9-17). New York: Cambridge University Press.

Johnson, D. W., Johnson, R. T., \& Smith, K. A. (1998). Cooperative learning returns to college: What evidence is there that it works? Change, 30(4), 26-35. http://dx.doi.org/10.1080/00091389809602629

Kohonen, V. (1992). Experiential language learning: Second language learning as cooperative learner education. In D. Nunan (Eds.), Collaborative language learning and teaching (pp. 14-39). Cambridge: Cambridge University Press. 
Lantolf, J. P., \& Thorne S. L. (2007). Sociocultural theory and second language learning. In B. VanPatten \& J. Williams (Eds.), Theories in second language acquisition: An introduction (pp. 201-224). Mahwah, NJ: Lawrence Erlbaum.

Lantolf, J. P. (2006). Sociocultural theory and L2: State of the Art. Studies in Second Language Acquisition, 28(1), 67-109. http://dx.doi.org/10.1017/S0272263106060037

Leow, R. P. (1997). Attention, awareness, and foreign language behavior. Language Learning, 47(3), 467-505. http://dx.doi.org/10.1111/0023-8333.00017

Leow, R. P. (2007). Input in the L2 classroom: An attentional perspective on receptive practice. In R. M. Dekeyser (Eds.), Practice in a second language: Perspectives from applied linguistics and cognitive psychology (pp. 21-50). Cambridge: Cambridge University Press. http://dx.doi.org/10.1017/CBO9780511667275.004

Lopez-Serrano, S., M. Manchon, R., \& Santos, M. (2010). The differential effects of two types of direct written corrective feedback on noting and uptake: reformulation vs. error correction. International Journal of English Studies, 10(1), 1-20.

Mitchell, R., \& Myles, F. (2004). Second language learning theories (2nd ed.). London: Arnold.

Min, H.-T. (2006). The effects of trained peer review on EFL students' revision types and writing quality. Journal of Second Language Writing, 15(2), 118-141. http://dx.doi.org/10.1016/j.jslw.2006.01.003

Mory, E. H. (2004). Feedback research revisited. In D. H. Jonassen (Eds.), Handbook of research on educational communications and technology (pp. 745-783). Mahwah, NJ: Lawrence Erlbaum.

Nelson, G. L., \& Carson, J. G. (1998). ESL students' perceptions of effectiveness in peer response groups. Journal of second language writing, 7(2), 113-131. http://dx.doi.org/10.1016/S1060-3743(98)90010-8

Nunan, D. (1992). Introduction. In D. Nunan (Eds.), Collaborative language learning and teaching (pp. 1-10). Cambridge: Cambridge University Press. http://dx.doi.org/10.1515/9783110850512.1

Pawlak, M. (2013). Error correction in the foreign language classroom: Reconsidering the issues. Springer Science \& Business Media.

Poulos, A., \& Mahony, M. J. (2008). Effectiveness of feedback: The students' perspective. Assessment \& Evaluation in Higher Education, 33(2), 143-154. http://dx.doi.org/10.1080/02602930601127869

Qi, D. S., \& Lapkin, S. (2001). Exploring the role of noticing in a three-stage second language writing task. Journal of Second Language Writing, 10(4), 277-303. http://dx.doi.org/10.1016/S1060-3743(01)00046-7

Rassaei, E. (2013). Corrective feedback, learners' perceptions, and second language development. Elsevier, 41, 472-483. http://dx.doi.org/10.1016/j.system.2013.05.002

Richards, C. J. (2006). Series editor's preface. In S. G. McCafferty, G. M. Jacobs, \& C. Iddings (Eds.), Cooperative learning and second language teaching (p. ix). New York: Cambridge University Press.

Richards, C. J., \& Rodgers, S. T. (2001). Approaches and methods in language teaching. Cambridge: Cambridge University Press. http://dx.doi.org/10.1017/CBO9780511667305

Riddiford, N. (2006). Collaborative error correction: How does it work? Prospect, 21(3), 26-37.

Robinson, P. (1995). Attention, memory, and the "noticing" hypothesis. Language Learning, 45(2), 283-331. http://dx.doi.org/10.1111/j.1467-1770.1995.tb00441.x

Rollinson, P. (2005). Using peer feedback in the ESL writing class. ELT Journal, 59(1), 23-30. http://dx.doi.org/10.1093/elt/cci003

Sheen, Y., \& Ellis, R. (2011). Corrective feedback in language teaching. In E. Hinkel (Ed.), Handbook of Research in Second Language Teaching and Learning (Volume 2, pp. 593-610). New York: Routledge.

Shintani, N., \& Ellis, R. (2013). The comparative effect of direct written corrective feedback and metalinguistic explanation on learners' explicit and implicit knowledge of the English indefinite article. Journal of Second Language Writing, 22(3), 286-306. http://dx.doi.org/10.1016/j.jslw.2013.03.011

Schmidt, R. W. (1990). The role of consciousness in second language learning. Applied Linguistics, 11(2), 206-226. http://dx.doi.org/10.1093/applin/11.2.129

Schmidt, R. (2001). Attention. In P. Robinson (Eds.), Cognition and second language instruction (pp. 3-32). Cambridge: Cambridge University Press. http://dx.doi.org/10.1017/CBO9781139524780.003 
Storch, N. (2001). How collaborative is pair work? ESL tertiary students composing in pairs. Language Teaching Research, 5(1), 29-53. http://dx.doi.org/10.1177/136216880100500103

Svalberg, A. M. L. (2009). Engagement with language: interrogating a construct. Language Awareness, 18(3/4), 242-258. http://dx.doi.org/10.1080/09658410903197264

Tomlin, R. S., \& Villa, V. (1994). Attention in cognitive science and second language acquisition. Studies in Second Language Acquisition, 16(02), 183-203. http://dx.doi.org/10.1017/S0272263100012870

Tuan, L. T. (2010). Infusing cooperative learning into an EFL classroom. English Language Teaching, 3(2), 64-77. http://dx.doi.org/10.5539/elt.v3n2p64

Tsui, A. B., \& Ng, M. (2000). Do secondary L2 writers benefit from peer comments? Journal of second language writing, 9(2), 147-170. http://dx.doi.org/10.1016/S1060-3743(00)00022-9

Van Beuningen, C. (2010). Corrective feedback in L2 writing: Theoretical perspectives, empirical insights, and future directions. International Journal of English Studies, 10(2), 1-27.

Wee, S. \& Jacobs, G. M. (2006). Implementing cooperative learning with secondary school students. In S. G. McCafferty, G. M. Jacobs, \& C. Iddings (Eds.), Cooperative learning and second language teaching (pp. 113-133). New York: Cambridge University Press.

Wigglesworth, G., \& Storch, N. (2012). Feedback and writing development through collaboration: A socio-cultural approach. In R. Manchon (Eds.), L2writing development: Multiple perspectives (pp. 69-101). New York: De Gruyter Mouton. http://dx.doi.org/10.1515/9781934078303.69

Yang, M., Badger, R., \& Yu, Z. (2006). A comparative study of peer and teacher feedback in a Chinese EFL

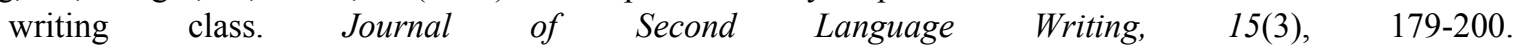
http://dx.doi.org/10.1016/j.jslw.2006.09.004

\section{Copyrights}

Copyright for this article is retained by the author(s), with first publication rights granted to the journal.

This is an open-access article distributed under the terms and conditions of the Creative Commons Attribution license (http://creativecommons.org/licenses/by/3.0/). 